\title{
Ethnobotanical survey of the flora of Maidan Valley, Lower Dir District, Khyber Pakhtunkhwa Province, Pakistan
}

\author{
Muhammad Irfan ${ }^{1}$, Izaz Ali ${ }^{2}$ and Rabia Afza Kashif ${ }^{2}$ \\ ${ }^{1}$ Department of Botany, Abdulwalikhan University, Mardan, Pakistan \\ ${ }^{2}$ Department of Botany, Hazara University, Mansehra, Pakistan
}

\section{Article history}

Received: 05 February 2018

Accepted: 03 April 2018

Published: 05 April 2018

(c) Irfan et al (2018)

Editor

K K Sabu

\section{Publisher}

Horizon e-Publishing Group

Correspondence

Muhammad Irfan

凶mirfan310@yahoo.com

\begin{abstract}
An ethnomedicinal survey of the plants of Maidan Valley, Lower Dir District, Khyber Pakhtunkhwa Province, Pakistan was carried out to collect and document the information available with the local people. A total of 43 ethnomedicinal taxa were identified, that were distributed among 40 genera and 31 families and utilized by the local people for the treatment of various ailments. Amongst them thirty eight taxa were Angiosperms that included thirty four Dicotyledons and four Monocotyledons. The remaining five taxa comprised of two Pteridophytes, two Gymnosperms and one Fungus. Lamiaceae was the largest family with seven taxa, Apiaceae, the second largest family with three taxa followed by Amaranthaceae, Berberidaceae, Rhamnaceae, Rutaceae and Violaceae having two taxa each. The remaining families viz. Anacardiaceae, Asteraceae, Buxaceae, Canabiaceae, Cucurbitaceae, Euphorbiaceae, Fagaceae, Fumariaceae, Geraniaceae, Juglandaceae, Liliaceae, Morchellaceae, Oleaceae, Papaveraceae, Papilionaceae, Punicaceae Rosaceae, Saxifragaceae and Solanaceae had one taxa each of ethnobotanical importance.. They were mostly used in the form of dicoctions and infusionsas remedies against respiratory diseases viz. asthma, bronchitis, emphysema and pneumonia, kidney and urinary problems, circulatory disorders and skin diseases.
\end{abstract}

\section{Keywords}

Ethnomedicine; Ethnobotany; Khyber Pakhtunkhwa; Maidan Valley

\section{Citation}

Irfan M, Ali I, Kashif R A. Ethnobotanical survey of the flora of Maidan Valley, Lower Dir District, Khyber Pakhtunkhwa Province, Pakistan. Plant Science Today 2018;5(2):68-71. https://dx.doi.org/10.14719/pst.2018.5.2.379

\section{Introduction}

Maidan Valley is situated in Dir Lower District of Khyber Pakhtunkhwa Province, Pakistan covering an area of $300 \mathrm{sq} \mathrm{km}$ and located between $34^{\circ}-37 /$ to $35^{\circ}-7 / \mathrm{N}$ Latitudes and $71^{\circ}-31 /$ to $72^{\circ}-14 / \mathrm{E}$ longitudes. Maidan Valley is dominated by the southern part of Hindukush Mountain Range that has an altitude of $1800-2000$ meters. Most of the population of the area is involved in farming, agriculture, horticulture and sericulture. The summer season is moderately hot, June and July are hottest months and in June the temperature ranges from $15.6^{\circ} \mathrm{C}$ to $32.5^{\circ} \mathrm{C}$. The winter season is cold and severe and the temperature decreases rapidly from November onwards. December, January and February are the coldest months, during which the temperature falls below $0^{\circ} \mathrm{C}$. During 2000, the average maximum and minimum temperature during the month of January were recorded as 


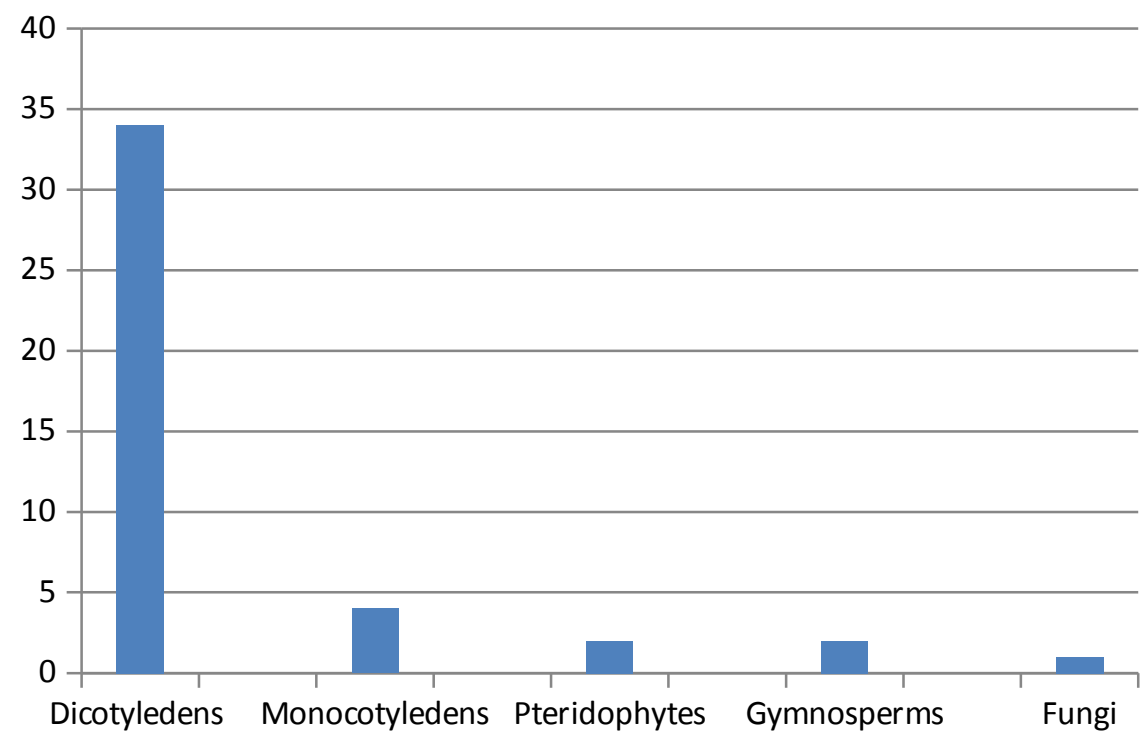

Fig. 1. Representation of different groups of plants species used ethnomedicinally in Maidan Valley

$11.2^{\circ} \mathrm{C}$ and $-2.4^{\circ} \mathrm{C}$ respectively [1]. The major crops grown are Triticum aestivum, Zea mays, Saccharum officinarum, Oryza sativa, Curcubita maxima, Hibiscus esculentus, Solanum nigrum, Lycopersicon esculentum and Allium cepa etc. The fruits grown in the region are Citrus medica, Juglans regia, Diospyros lotus, Prunus persica, Punica granatum, Malus pumila and Vitis vinifera. The most common Gymnosperms are Pinus roxburghii, Cedrus deodara and Taxus baccata while the common species of Angiosperms are Celtis australis, Isodon rugosus, Quercus incana, Mentha viridis, Acacia nilotica, Dodonaea viscosa, Justicia adhatoda, Tagetes minuta, Chenopodiastrum murale, Amaranthus viridis, Salvia officinalis, Ajuga bracteosa, Lamium album., Pterodophytes seen in the region are Pteris cretica, Pteris vittata, Thelypteris palustris, Adiantum incisum, Adiantum capillus-veneris, Adiantum caudatum, Cheilanthes subvillosa and Pteridium revolutum.

Ethnomedicine is the study of traditional medicine practiced by indigenous people and ethnic groups. Ethnomedicine serves the dual purpose of documenting the traditional knowledge and utilizing the same for the production of novel drugs. About $80 \%$ people of all over the world still depend on the traditional system of health care [2]. New taxa of immense medicinal importance have been reported from various places in Pakistan [3-16].

\section{Materials and Methods}

Field trips were conducted to various localities in Lower Dir District viz. Zaimdara, Babagam, Shegai, Balokhan, Goharkat, Karin, Dabaku, Lacha and Uthala during the period. Previously prepared questionnaires were handed out to local inhabitants. The informants consisted of farmers, aged women, religious people, medicinal plant dealers and hakims. Mostly older people and herbal practitioners were consulted for obtaining the valuable information as they were found to possess a lot of knowledge about the local uses of plants and their important medicinal and traditional uses. The plant specimens were collected, photographed, tagged, pressed and finally mounted on standard herbarium sheets. Identification of the plants was done with the help of Flora of Pakistan [17]. The mounted specimens were deposited in the herbarium of Hazara University Mansehra, Pakistan [HUP].

\section{Results and Discussion}

A total of 43 ethnomedicinal taxa were identified, that were distributed among 40 genera and 31 families and utilized by the local people for the treatment of various ailments. Amongst them thirty eight taxa were Angiosperms that included thirty four Dicotyledons and four Monocotyledons. The remaining five taxa comprised of two Pteridophytes, two Gymnosperms and one Fungus (Fig. 1). Lamiaceae was the largest family with seven taxa, Apiaceae, the second largest family with three taxa followed by Amaranthaceae, Berberidaceae, Rhamnaceae, Rutaceae and Violaceae having two taxa each. The remaining families viz. Anacardiaceae, Asteraceae, Buxaceae, Canabiaceae, Cucurbitaceae, Euphorbiaceae, Fagaceae, Fumariaceae, Geraniaceae, Juglandaceae, Liliaceae, Morchellaceae, Oleaceae, Papaveraceae, Papilionaceae, Punicaceae Rosaceae, Saxifragaceae and Solanaceae had one taxa each of ethnobotanical importance (Fig. 2). Almost all parts of the plants were utilized (Fig. 3). The most commonly used plant part however was the leaf. In $37.21 \%$ of the reported plants, the useful part was the leaf. In seven of the plants, roots were used and in six seeds were used. In Pistacia integerrima, Thymus linearis and Ziziphus jujuba the fruits were utilized. Whole plants were 


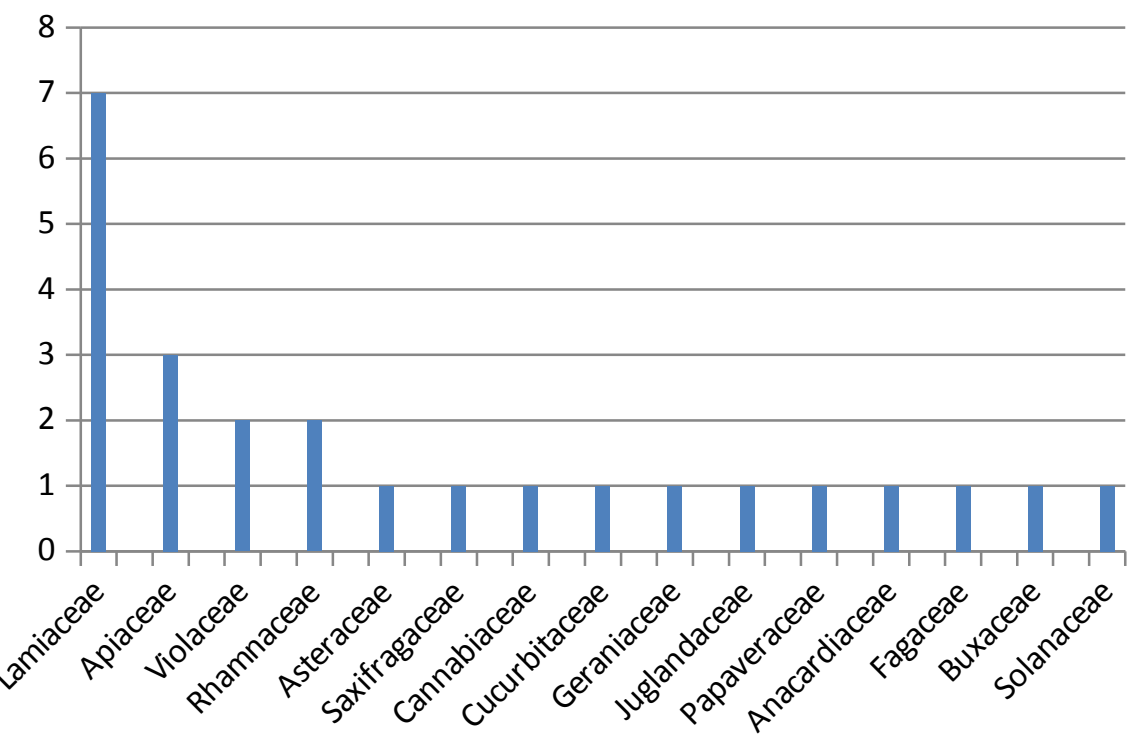

Fig. 2. Representation of ethnomedicinally important families in Maidan Valley

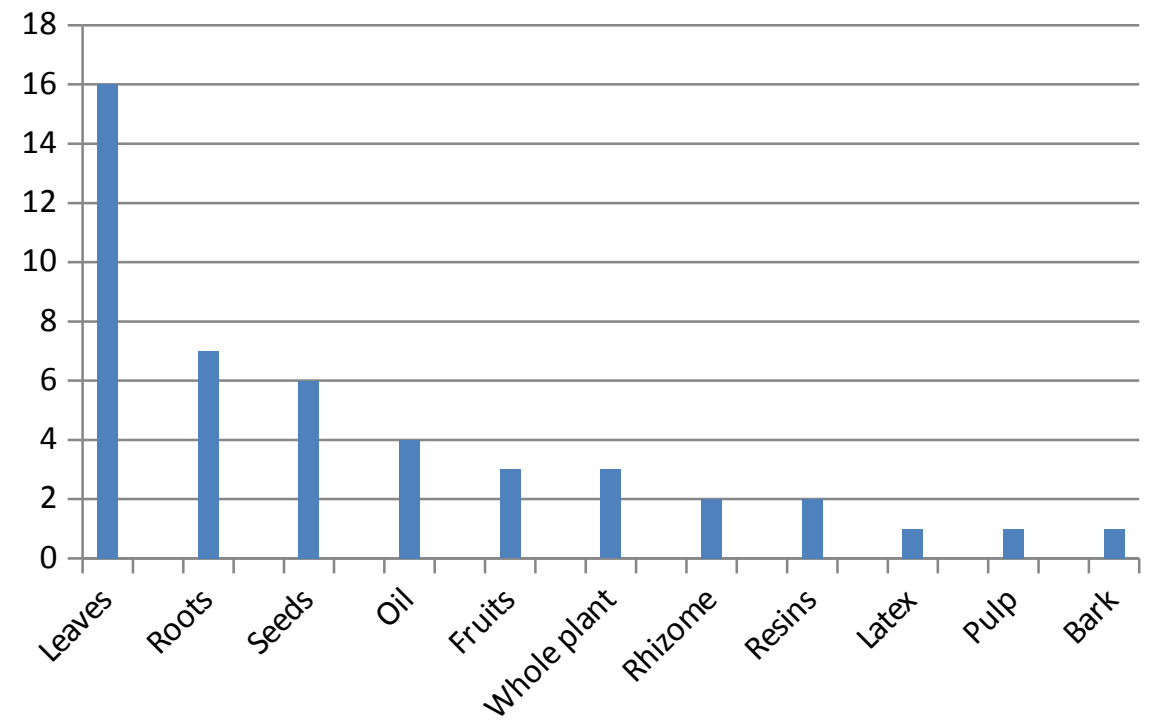

Fig. 3. Representation of different part/s used ethnomedicianally of plant species in Maidan Valley

used in the case of Viola biflora, Equisetum arvense and Morchella esculenta. Other plant parts such as the rhizome, bark, latex and resin were also made use of in the preparations. The results are summarized in Supplementary Table 1 Among the 43 plants documented, thirty eight (88.37\%) were collected from the wild while the remaining five (12.63\%) viz. Ammi visnaga, Coriandrum sativum, Foeniculum vulgare, Papaver somniferum and Punica granatum were cultivated.

\section{Conclusion}

It can be concluded from the current study that there is still widespread use of medicinal plants and traditional healing practices among the inhabitants of Maidan Valley. While some plants were used in the treatment of ailments like. respiratory infections, urinary problems, sterility, skin disorders, hepatitis, diabetes and fever others were used as tonics and in hair care. Greater utilization of the plants is suggested, keeping in mind its sustainability. The plants reported here are potential candidates for drug development and can be subjected to further investigations.

\section{Acknowledgement}

The authors are really thankful to the inhabitants of Maidan Valley, Lower Dir District, Khyber Pakhtunkhwa, Pakistan for sharing their precious traditional knowledge with us.

\section{Conflict of interest}

The authors declare no conflict of interest. 


\section{Authors' contribution}

MI conducted the experiment and carried out the statistical analysis, IA designed the experiment and RA structured and wrote the manuscript.

\section{References}

1. Anonymous. Biodiversity Action Plan for Pakistan. Printed: Imprint (Pvt) Ltd., Rawalpindi Cantt., Pakistan; 2000.

2. Ahmad $\mathrm{H}$. The medicinal plants of Tharparker, WWF - Peshawar, Pakistan; 2000.

3. Ali A, Rashid M, Sultan A, Irfan M. Anisochilus carnosus (L. f.) Wall. ex Benth. (Lamiaceae) - a new generic record for Pakistan. Plant Science Today 2017;4(3):102-105. http://dx.doi.org/10.14719/pst.2017.4.3.316.

4. Hazrat A, Shah J, Ali M, Iqbal I. Medicinal value of Ranunculaceae of Dir valley. Pak. J. Bot. 2007;39(4):1037-1044.

5. Siraj-ud-din S M, Mir A K, Ikramullah. Traditional use of medicinal herbs for gastrointestinal disorders in Maidan Valley, District; Dir, WWF. Proc. Int. Workshop, Islamabad. Pp: 125-131; 2003.

6. Manan Z, Sirajuddin, Razzaq A, Islam M, Ikramullah. Diversity of medicinal plants in Wari subdivision district Upper Dir, Pakistan. Pak. J. Pl. Sci. 2007;13 (1):21-28.

7. Ahmad I, Ibrar M, Barkatullah, Ali N. Ethnobotanical study of tehsil Kabal, Swat District, KPK, Pakistan. Hindawi Publishing Corporation. J. Bot. 2011(2011):1-9.

8. Mahmood A, Malik R N, Shinwari Z K, Mahmood A. Ethnobotanical survey of plants from Neelum, Azad Jammu \& Kashmir, Pakistan. Pak. J. Bot. 2011;43:105-110.
9. Murad W, Ahmad A, Abdullah Gilani S, Khan M A. Indigenous knowledge and folk use of medicinal plants by the tribal communities of Hazar Nao Forest, Malakand District, North Pakistan. Journal of Medicinal Plants Research 2011;5(7):1072-1086.

10. Jan G, Khan M A, Gul F, Ahmad M, Jan M, Zafar M. Ethnobotanical study of common weeds of Dir Kohistan valley, Khyber Pakhtunkhwa, Pakistan. Pak. J. Weed Sci. Res. 2000;16(1):81-88.

11. Ali H, Qaisar M. The Ethnobotany of Chitral Valley, Pakistan with Particular Reference to Medicinal Plants. Pak. J. Bot. 2000;41(4):2009-2041.

12. Hussain F, Islam $M$, Zaman A. Ethnobotanical profile of plants of Shawer Valley, Distt; Swat, Pakistan. Int. J. Biotech. 2006;3:301-307.

13. Haq I, Hussein Z. Medicinal Plants of Manshera District., NWFP Pakistan. Hamd. Med. 1993;34(3):6369.

14. Irfan M, Ahmad I, Saeed S H. Traditional medicinal plant knowledge of some spermatophytes of Samar Bagh Valley, Lower Dir district, Pakistan. Plant Science Today 2017;4(4):151-153. doi: 10.14719/pst.2017.4.4.334

15. Ahmad I, Irfan M, Ali I, Khan J, Saeed S H, Gulfaraz A. Checklist of some medicinal plants of district Lower Dir, Pakistan, IASET: Journal of Agricultural \& Bio-Chemical Science 2016;1:15-22.

16. Gul A, Alam J, Ahmad H, Irfan M. An updated checklist of Pteridophytes of district Mansehra, Khyber Pukhtunkhwa-Pakistan. Plant Science Today 2006;3(2):237-247.

http://dx.doi.org/10.14719/pst.2016.3.2.220.

17. Ali S I, Qaiser M, Nasir E. Flora of Pakistan, Department of Botany, University of Karachi, Pakistan 1-210;1970-2004. 